Jan Kubik

April 2012

\title{
"Cultural approaches"
}

The Handbook of Transformation Research, edited by Raj Kollmorgen, Wolfgang Merkel and Hans-Jürgen Wagener. Publisher: VS-Verlag für Sozialwissenschaften.

Introduction

Since change is the fundamental reality of human existence, society is better conceived of in terms of "becoming" than "being" (Sztompka 1993b). But the speed and sequence of becoming varies. Sometimes its pace is so slow that the society appears to be an inert structure, sometimes it is gradual and evolutionary, and - much more rarely - it is rapid, revolutionary. Transformations, as specific types of rapid social change (and specific modes of societal becoming) are defined in this volume broadly as "fundamental societal upheavals leading to system change." The concept does not, therefore, refer to all kinds of social change, nor does it refer only to political transformations. A change is a transformation if it has at least two features: comprehensiveness (it effects all or most areas of life) and a relatively rapid pace (it is experienced as faster than the "normal" flow of life). Of particular interest are transformations that occur as a result of implementation of political projects, and thus are to a degree directed. In these cases we need to study both their intended and unintended consequences.

The task of this chapter is to delineate the role of culture in transformations construed as rapid and comprehensive societal changes that are triggered and/or coordinated by political projects. Since much depends on the definition of culture, a notoriously vague concept, some preliminary definitional work is in order. 
Culture

Culture refers to a multifaceted and complex dimension of social reality and is thus notoriously difficult to define. Here I introduce only two analytical distinctions that help to make this concept more useful for research. First, we need to distinguish between global and selective (delimited) definitions of culture. Culture conceived globally refers to all building blocks of human (collective) life that are not transmitted genetically. Tylor provided the most influential definition of this kind: "Culture, or civilization, taken in its broad, ethnographic sense, is that complex whole which includes knowledge, belief, art, morals, law, custom, and any other capabilities and habits acquired by man as a member of society" (Tylor 1958 [1871]: 1); similar definitions were dominant in the nineteenth century evolutionary sociology and anthropology. Given the comprehensiveness of such definitions, their users would see transformations as $e x$ definitio cultural processes.

Dissatisfied with the unwieldy scope of global definitions of culture, scholars set out to narrow them. Two broad strategies of conceptual delimitation emerged: socio-psychological and semiotic. The first strategy, dominant in political science, leads to the a definition according to which culture "consists of attitudes, beliefs, values and skills which are current in an entire population, as well as those special propensities and patterns which may be found within separate parts of that population" (Almond and Powell 1966:23). (Politically) relevant attitudes or "subjective political orientations" are attributes of individual minds and are composed of cognitive, evaluative, and emotive elements. They are usually studied via surveys and interviews. Adherents of the second strategy, semiotic, conceive culture as a web of meaning, “... an historically transmitted pattern of meanings embodied in symbols, a system of inherited 
conceptions expressed in symbolic forms by means of which men communicate, perpetuate, and develop their knowledge about and attitudes toward life" (Geertz 1973:89). The study of the relationship between culture and politics in this approach consists primarily of the systematic interpretation of an ensemble of politically relevant texts produced in given society and accessible in public spaces. Of particular interest are meanings that provide evaluations of the world and provide scripts (or scenarios) of/for action.

To illustrate the gap between the two conceptualizations it is enough to contrast the different research agendas associated with each of them: whereas within the socio-psychological approach we study the existing syndromes of attitudes that, for example, facilitate or obstruct the building of democracy, within the semiotic approach we may focus on cultural practices, such as rituals, production of texts, putting on performances, etc. through which political entrepreneurs try to influence people's minds to promote (or demonize) "democracy."

Each research agenda is associated with a specific, highly articulated sub-disciplinary intellectual tradition based on a distinctive set of categories, modes of argument, and techniques of data gathering. What can bridge them is an assumption that culture is formed and forms individual minds (attitudes) via communication. In the most basic model, an act of communication is composed of three elements: sender, message, and receiver. Semiotic approaches focus on meaning and its formation thus their practitioners tend to study the first two elements: message(s) and sender(s). The third element of the communication triad, receiver(s) can be studied in many ways, but most popular and influential are surveys of attitudes (views, opinions, etc.). We need to focus on all three elements to describe and explain how meanings are generated, transmitted, and internalized to become motivators of (political) actions. Studies of political culture that rely exclusively on surveys of attitudes are incomplete; they do not provide 
information on the producers of cultural messages and the meaning of messages themselves. They do not show how culture "works;" they only uncover its effects.

The problem of prime movers of transformation

One of the great debates in the history of social thought is about the prime movers of social change (Sztompka 1993b:20-22). Is it ideas/culture (idealists) or economic forces (materialists)? The issue was influentially debated by Skocpol (1994) and Sewell (1994). The latter criticized the former for neglecting ideologies as autonomous factors that are "constitutive of the social order" as they "inform the structure of institutions, the nature of social cooperation and conflict, and the attitudes and predisposition of the population" (Sewell 1994:173). The debate, which in the hands of Skocpol and Sewell had a strong structuralist tenor, has been recast in the "agentic" direction and tends to focus these days on concrete agents and their actions, such as political entrepreneurs who manipulate culture to realize their interests (Archer 1996:73). Such agency-driven explanations are de rigueur in today's social science. The task is not to identify abstract cultural (ideational) or materialist causes of change, but rather to answer several questions about the specific agents of change and their semiotic strategies. Four such questions seem to be fundamental: (1) Are agents of change acting deliberately to engineer transformation or does change occurs as a result of many unintentional and uncoordinated actions? (2) If agents act deliberately, do they have enough power to generate transformation? (3) If they do, does the change in one area (say, culture) necessarily have causal consequences in another area (economy) (Bell's (1978) concept of disjunctions suggests that not always)? (4) Do (observed) agents focus deliberately on re-defining the cultural landscape of the society whose change they 
are trying to engineer or do they merely respond by trying to "find sense" in the world that is changing due to other agents' actions driven by non-cultural considerations (economic or political)? Studies animated by these four questions (see, for example, Harvey 1989) offer more productive ways to gauge the role of culture in transformations than the old-fashioned attempts to locate the prime mover in abstractly conceived culture (ideas) or material forces (economy).

In a research program consistently focused on agency, the question of how change in the network of meanings - without which a human society is inconceivable - is affected must be asked in a specific way. Endogenous "cultural" change is a result of invention and introduction of new meaning to a given cultural field. The change means the proactive rearrangement of the meaning structure and, for example, the provision of novel values and scripts of action to the actors (think about religious "revolutions" such as the Reformation). For example, we want to assess the impact of the changed structure of meanings (the emergence of the neoliberal blueprint) on economic activity (say, patterns of taxation) or political action (say, challenges to the social-democratic order). Cultural change is induced exogenously when a cultural entrepreneur offers a new meaning prompted by a clearly specified, prior economic or political event, such as market collapse or a violent coup d'état. The rearrangement of meaning structure in such situations is reactive and is designed to help actors cope with economic or political changes influencing their lives.

How can we think about cultural change (as a trigger or component of transformation) when culture is conceived as a syndrome of attitudes, the standard conceptualization in political science? It is difficult if not impossible, unless we are satisfied with a model of the internal process of attitudinal change. As a result, scholars using this approach (relying on surveys or interviews) tend to think about "culture" as a constraint (obstacle) rather than a resource for 
successful political and/or economic transformations. We need to assume that a change in a person's attitudes is a component of a broader transformation only if at least three conditions are fulfilled: (1) an "individual" change (invention of a new meaning or evaluation) is communicated in some cultural medium, so others can learn about it, (2) the communicator reaches a sizeable audience, and (3) a sufficient number of people, exposed to the new message, experience changes or adjustments in their attitudes (views, definitions of reality, etc.). Thus, to study cultural change we must focus on the process of communication and observe what and how meaning is being communicated. In short, we need a semiotic approach.

Three stages of transformation and culture

It is customary to conceptualize transformations, including those that transpired in Eastern Europe and the former Soviet Union, as being composed of three stages: breakdown (or deconstruction) of the old system, power transfer, and consolidation of a new system. Culture appears to play a different role at each stage.

Culture and decomposition of the old regime/system

The study of culture as a factor driving or contributing to the deconstruction of the old regime has a venerable tradition. Hunt (1984), in her path-breaking analysis of the French Revolution, showed that before the ancient regime fell apart as a result of social upheavals and political actions, it was dismantled ideologically or culturally. As she argued, "political practices were not simply the expression of 'underlying' economic and social interests. Through their 
language, images, and daily political activities, revolutionaries worked to reconstitute society and social relations" (1984:12). Inspired by her work, Kubik (1994) put forth a theory that cultural factors, such as the "festival of freedom" initiated by John Paul II's visit to his native land in 1979, were prime movers of the collapse of state socialism in Poland (where the whole process commenced). Almost all studies in this group rely on semiotic approaches and treat culture as the domain of symbols and discourses that are manipulated by cultural entrepreneurs who are trying to affect transformation by modifying people's image of the world. The decomposition of the dominant system is seen, primarily, as the rapid or gradual reconstruction of cultural maps (webs of meanings) that not only provide social actors with new goals and ideals but also suggest to them novel scripts of action whose efficacy as engines of transformations increases during unsettled periods (Swidler 1996).

Culture and power transfer

At the first sight, culture does not seem to be at the center of action during this stage. But this assumption is wrong. The actual power transfer happens either as a violent overthrow or as a negotiated change of ruling elites (at least initially). Under the former scenario, culture provides scripts for both goals and means of the revolution (consider Lenin's: "There can be no revolution without theory" (Malia 2006:250)), thus also for what to do with the deposed rulers and vanquished "enemies." If the transfer is negotiated, two factors need to be studied. First are cultural scenarios of "negotiating" that may be more or less effective in facilitating the actual course of negotiations. Most important seems to be the culturally-modeled proclivity of negotiators to switch from seeing the "other side" as (inscrutable) enemies to accepting the idea 
that they are (trustworthy) partners. Second, cultural scenarios current in the society at large (syndromes of attitudes) either facilitate or obstruct popular acceptance of the particular mode of power transfer negotiated by the elites.

Importantly, there seems to exist a universal phenomenon of the post facto politicization of memory of power transfer. Invariably, during the stage of consolidation, some political entrepreneurs engage in semiotic maneuvers (acts of interpretation) designed to generate and promote such interpretations of the negotiations that are congruent with their ideological visions and/or advance their political objectives. Some politicians of the new order define some or all negotiators as "traitors" and call for punishing or ostracizing them.

Culture and consolidation of a new system

There are three broad research programs in the study of the relationship between culture and consolidation, the last stage of transformations.

By far the most developed is the program in which culture is seen predominantly if not exclusively as a set of attitudes, at least partially inherited from the defunct old regime. Culture thus conceived constitutes a constraint (obstacle) for (economic or political) transformations; it is theorized as sort of cultural sand that slows down and occasionally derails the functioning of the transformational machine. In the field of post-communist studies several authors explore the incompetence of a given society (some or many of it members), its lack of preparedness for a new political or economic system instituted by someone else (the elites, external actors, etc.). For example, there are influential studies of weak "pro-democratic" political cultures (for example in Russia) that obstruct progress of democratization and/or of statist-welfarist orientations that 
weaken support for market-oriented reforms (Klingemann, Fuchs and Zielonka, eds. 2006;

Pollack, Jacobs, Muller, and Pickel, eds. 2003; Whitefield, ed. 2005). Arguably, the biggest weakness of this program is the lack of attention to people's definition of "democracy;" we know how much they support or reject it, but we do not know how they understand it. Thus we do not know if they support or reject the same thing.

Some scholars work with the concept of Homo Sovieticus, a type of human being shaped by communism and having hard time adjusting to the new situation. Sztompka (1993a) identified seven values that constitute a specific culture, developed under state socialism and at least partially responsible for turning (some) members of Homo Sapiens into Homo Sovieticus. Representatives of this sub-specie cannot easily become "proper" participants in a system based on democracy and market economy because they are held down by civilizational incompetence. Among the values identified by Sztompka are "the lack of respect for law, institutionalized evasions of rules, distrust of authorities, double standards of talk and conduct, glorification of tradition, idealization of the West" (1993a:89). While undoubtedly there are individuals who may espouse some or all of these values, ethnographic studies of local or regional cultures show that whole communities rarely if ever look as dismal as the concept suggests. Subtler studies belonging to this research program are designed to determine which groups in the society possess sufficient cultural competence (cultural capital) to carry out or at least support reform programs and which are unprepared for such endeavors. Such works seem to belong to the research program on "coping" and are discussed below.

The discussion of the role of cultural factors - conceptualized as a set or syndrome of attitudes - during the consolidation of a new regime is inconclusive. For most authors democracy is not possible or at least very difficult to sustain without "pro-democratic" cultural prerequisites. 
They argue that certain attitudes and orientations are clearly correlated (although the establishment of causal arrows may be difficult) with the successes/failures of liberal-democratic reforms. A smaller group of scholars conclude, however, that cultural traditions are inconsequential for the establishment of liberal democracy and ascribe causal import only or predominantly to economic and political factors. Cultural changes here are construed as epiphenomenal.

The second set of approaches focuses on culture as an area that provides scenarios for (economic and political) transformations. Culture is approached here as a set of (ideological) templates or blueprints (thus discourses, texts, symbols, etc.) that are developed and propagated by transformational "engineers." Kennedy (2002) contributes to this literature with two important concepts of transition culture (founded on the precepts of neoliberalism) and cultural formations of postcommunism (for example nationalism) that articulate in complex, often contradictory ways, with transition culture. Cultural factors are seen here predominantly as resources and are analyzed modo semiotico (via some form of content analysis) as texts that offer templates or scripts of action.

Transition culture built around neoliberalism provides the dominant blueprint for postcommunist transformations and its proponents have been puzzled that democracies and vibrant economies did not spring out right after the fall of state socialism. Absent the constraining influence of an insidious ideology and authoritarian suppression, the formerly communist countries should - it has been assumed - soon join Western Europe as advanced industrial economies with accountable and transparent governments. This has not happened and those who assume that liberal democracy and market economy are the natural and optimal telos of human organization are puzzled. It seems that this assumption goes hand in hand with the economist- 
materialist way of thinking that culture merely follows economic and political organization with no generative capacity of its own, thus it should change rather swiftly and painlessly. But faced with the necessity of explaining many failures of the neoliberal project, quite a few analysts have turned to culture. Actually, they posit the existence of two, competing, cultures: transition culture of the "engineers" consisting of a set of cultural scenarios needed to realize the goals of transformations and a syndrome of (popular) attitudes that slow down or derail their realization.

Scholars adhering to the broadly conceived semiotic paradigm study both cultural/ideological apologies of neoliberalism proposed and enforced by transformational engineers and challenges to neoliberal transition culture offered by political leaders of oppositional parties (Urban 2010), social movements, and protest actions (see for example Kennedy 2002; Tornquist-Plewa and Stala, eds. 2011). Such challenges have been coming from both the left and the right of the ideological spectrum: critical (neo)Marxist, feminists or postmodern discourses represent the former; various forms of nationalism, right-wing populism, and religious traditionalism (not necessarily fundamentalist) - the latter. But, again, the authors of consequential cultural scripts are identified almost exclusively among various elites and the media or school systems they control.

Researchers belonging to the third group - a diverse group, methodologically and theoretically - try to move beyond this focus on elites and study cultures construed as reservoirs of scenarios (objectified cultural capital) and/or syndromes of "dispositions of the mind and body" (embodied cultural capital) (Bourdieu 1983) developed by and available to "ordinary" people who need to cope with intended and unintended consequences of transformations. To put the essence of this approach into sharp relief it is useful to distinguish three forms of culture. First, there is culture as a set of grand scenarios (blueprints, ideological frames, etc.) discussed 
above. Second, there is culture as a syndrome of attitudes (reconstructed from representative surveys and represented by statistical means) that is to some extent at least inherited from the old system. The third type of culture is usually unrecognized and understudied. This is the world of mostly local, vernacular cultures (cultural capitals) - inherited from the pre-1989 world, invented ab novo, or more or less skillfully woven from old and new elements - that provides people in the post-communist countries with scenarios of action that guide them in navigating the emerging social and political landscapes.

What is therefore most interesting about this approach is that without denying the (at least potential) causal significance of ideological challenges to neoliberal hegemony, its practitioners (mostly anthropologists and sociologists) focus on non-ideological - particularly local discourses and "anti-hegemonic" local/regional practices. Instead of studying theoretical debates within a community of experts, or ideological debates among national politicians, researchers attend to the people living through post-communist transformations that produce massive political, economic, social and cultural dislocations. In order to understand the nature of these changes at the level of practice - how people facilitated, resisted, integrated or remain untouched by geopolitical reorganization, market and electoral reforms, and ideological shifts - scholars study vernacular ways of dealing with specific social problems. Rather than asking what institutions transformational engineers are building and how, with their help, "capitalism and/or democracy can be built" (Kennedy 2002:22), this research program focuses on how "ordinary" people and/or their often local leaders (Petro 2004) develop and deploy cultural, social and political resources in the remediation of shared concerns. What is studied are actual strategies that empower people below the radar of various "officialdoms" and are often concocted as ad hoc mixtures that draw on both "old" and "new" cultural scenarios (including religious, see 
Hann, ed. 2010). Researchers take stock of discourses generated within and intertwined with the practices of everyday life, whose genealogies are local or regional, and whose ideological elaboration may be minimal. In brief, this research program does not negate that political mobilization informed by grand ideological frames is the most readily recognized expression of popular agency, but it also recognizes that people engage in low-key yet highly organized activity that combines "formal/legal," "semi-legal" and "informal/illegal" strategies, informed by historically shaped, often informally transmitted, and usually locally available cultural scripts of action.

Theory of cultural trauma and the theory of delayed (cultural) counter-transformation.

There are two notable theories of the cultural dimension of post-communist transformations. The theory of cultural trauma, proposed by Sztompka working in collaboration with several colleagues (Alexander et al. 2004), treats the regime transformation as a traumatogenic change that effects the society on several levels, including its "axio-normative and symbolic belief systems" (2004:161). Sztompka argues that people coping with the trauma of transformation can employ several strategies, but eventual success comes from developing new cultural tools. When this happens "in spite of immediate negative, painful consequences" cultural trauma "shows its positive, functional potential as a force of social becoming" (2004:194). Of course, the traumatic sequence may end up also in cultural destruction. This well-developed theory utilizes both conceptualizations of culture, socio-psychological and semiotic, and theorizes the role of cultural factors as both resources and obstacles to transformation. 
Another theory, merely signaled in various works, can be called delayed cultural countertransformation. It is suggested by the events of the 2005-2012 period during which several countries, most notably in Hungary, experience radical disruption of the transformational process and the decisive turn of the political field and popular culture to the right. The explanation of this momentous change in the process of consolidation is beyond this short essay, but it seems to have something to do with a combination of three factors: (1) transformational exhaustion caused often by the scandalous and corrupt behavior of the political elites (often ex-communists), (2) world economic crisis, and (3) the aggressive propagation of the right-wing political ideologies offered as panaceas for transformational problems.

Conclusions

Scholars try to explain why the course of post-communist transformations has been so uneven, often slow, and certainly costly. Why has it, in some places (Central Asia, Russia, Belarus), stalled or careened away from the "ideal course" onto the path of authoritarian reversal? And why, even in the most successful countries, there are persistent "problems," including underperforming sectors of the economy, unstable party systems, and weak civil societies? There is no agreement as to the sources and explanations of these problems. Most disagreements stem from the choice of data, concepts, and explanatory strategies. But regardless of the specific theoretical school, there seems to exist a more basic level of disagreement: the difference in the diagnosis of what constitutes the general source of "troubles" engendered by the transformations. This diagnosis, more or less explicitly formulated, comes as an answer to yet another question: why are the post-communist societies, with their own norms and routines, 
somehow out of sync with the institutional measures envisioned and implemented by the "reformers," foreign and domestic? Scholars offer many theories, yet in much of what they argue one can detect two broad "meta-theoretical" stances: social/cultural adjustment and institutional adjustment. Proponents of both views offer diagnoses (what is wrong?) and policy prescriptions (what is to be done?). The champions of social/cultural adjustment tend to locate the source of troubles in the post-communist societies, in the civilization incompetence of at least some of their segments, incompetence that is captured by a controversial concept of Homo Sovieticus, discussed above. The advocates of institutional adjustment see the principal source of problems in the reform programs, in their design or implementation, or both. Accordingly, while the former seek to formulate programs of social renewal that are aimed at changing the people so they can "fit" the indispensable institutions, the latter would rather redesign the incoming institutions so they can "fit" the people.

There exists, however, another conceptualization that helps to overcome the dichotomy of these two extreme positions. It is built around a careful and contextualized reconstruction of human agency. If in the view of social adjustors people (often in general) are seen as the "material" that needs to be fixed, and while institutional adjustors call for fixing reform programs and their implementation, in this new way of thinking people are seen as agents who are capable of fixing themselves and who, in fact, are always doing so. The proponents of this view emphasize agents' ability to adjust their strategies (we might call their theory: strategy adjustment) in order to cope with the changing environment. They reject the conceptualization of post-communist transformations as driven exclusively or mainly by external mechanisms. They also challenge broad, aggregate pictures of social reality in which actors, or at least "median" actors, are motivated by clues coming from "cultures" construed as attributes of large 
populations, such as nations (Homo Sovieticus in the post-communist region is the chief example). They always try to reconstruct actors' strategic creativity (agency) that is build out of elements (goals and scripts of action) sometimes provided by grand ideological programs (nationalism, religious fundamentalism) but always related to and interpreted in terms of identifiable vernacular cultures. Researchers practicing this approach shift their focus from how adequate or well-prepared people are to respond to transformations engineered at the top, to how people enact their vernacular visions of life and politics by responding to daily challenges engendered by transformations.

So, what have we learned about the most productive way of incorporating cultural analysis into the study of (post-communist) transformations? At a minimum such incorporation should follow the following principles. First, cultural elements should be conceptualized as both socio-psychological and semiotic phenomena. Second, cultural elements need to be treated as (potential) resources and/or constraints for/of political or economic action. Third, in each phase of transformation cultural factors play the critical role at a different level or structural location. During the deconstruction phase ideologies and discourses that challenge the very foundations of the system are critical; during power transfer "local" culture of the negotiating elites need to be focused on; and during consolidation researchers need to pay attention both to the highly articulate ideologies (populism, nationalism) propounded by political entrepreneurs for example during the post-2005 "ideological revolts" and to attitudes of non-elite actors as well as their strategies of coping informed by local, vernacular cultures. Fourth, the logic of mono-directional causality needs to be replaced with the logic of interdependence (of cultural, political, and economic factors). Fifth, cultural processes need to be construed as variably influencing 
transformations (sometimes this influence is more, sometimes less, pronounced), both temporarily and spatially.

In brief, culture per se can neither bring about democracy (or any other regime) nor bring it down; culture per se cannot do anything for it is an abstraction. Transformations are propelled forward or derailed only by actions of (some) people; in these actions they are guided or constrained by —among other resources and constraints_- "cultural elements" such as discourses, symbols, attitudes, etc.

Bibliography

Alexander, Jeffrey C., Ron Eyerman, Berhard Giesen, Neil J. Smelser, and Piotr Sztompka. 2004. Cultural Trauma and Collective Identity. Berkeley: University of California Press. Almond, Gabriel A, and G. Bingham Powell, Jr. 1966. Comparative Politics: A Developmental Approach. Boston: Little Brown.

Archer, Margaret S. 1996. Culture and Agency. The Place of Culture in Social Theory. Revised Edition. Cambridge: Cambridge University Press.

Bell, Daniel. 1978. The Cultural Contradictions of Capitalism. New York: Basic Books.

Bourdieu, Pierre. 1983. “Ökonomisches Kapital, kulturelles Kapital, sociales Kapital.” In Reinhard Kreckel, ed. Soziale Ungleichheiten (Soziale Welt, Sonderheft 2). Goettingen: Otto Schartz \& Co., pp. 183-98.

Geertz, Clifford. 1973. The Interpretation of Cultures. New York: Basic Books.

Hann, Chris, ed. 2010. Religion, Identity, Postsocialism. The Halle Focus Group 2003-2010. Halle/Saale: Max Planck Institute for Social Anthropology. 
Harvey, David. 1989. The Condition of Postmodernity. An Inquiry into the Origins of Cultural Change. Cambridge: Blackwell.

Hunt, Lynn. 1984. Politics, Culture and Class in the French Revolution. Berkeley: University of California Press.

Kennedy, Michael. 2002. Cultural Formations of Postcommunism. Emancipation, Transition, Nation, and War. Minneapolis: University of Minnesota Press.

Klingemann, Hans-Dieter, Dieter Fuchs and Jan Zielonka, eds. 2006. Democracy and Political Culture in Eastern Europe. London and New York: Routledge.

Kubik, Jan. 1994. The Power of Symbols Against the Symbols of Power. The Rise of Solidarity and the Fall of State Socialism in Poland. College Park: Penn State Press.

Malia, Martin. 2006. History's Locomotives. Revolutions and the Making of the Modern World. New Haven: Yale University Press.

Petro, Nicolai N. 2004. Crafting Democracy. How Novgorod Has Coped With Rapid Social Change. Ithaca: Cornell University Press.

Pollack, Detlef, Jorg Jacobs, Olaf Muller, and Gert Pickel, eds. 2003. Political Culture in PostCommunist Europe. Attitudes in New Democracies. Aldershot: Ashgate.

Sewell, William, Jr., 1994. "Ideologies and Social Revolutions: Reflections on the French Case." In Theda Skocpol, Social Revolutions in the Modern World. Cambridge: Cambridge University Press, pp. 169-98.

Skocpol, Theda. 1994. "Cultural Idioms and Political Ideologies in the Revolutionary Reconstruction of State Power” A Rejoinder to Sewell.” In Theda Skocpol, Social Revolutions in the Modern World. Cambridge: Cambridge University Press, 199-209. 
Swidler, Ann. 1986. "Culture in Action: Symbols and Strategies." American Sociological Review, 51 (April): 273-86.

Sztompka, Piotr. 1993a. "Civilizational Incompetence: The Trap of Post-Communist Societies." Zeitschrift fur Soziologie 22, 2 (April): 85-95.

Sztompka, Piotr. 1993b. The Sociology of Social Change. Oxford: Blackwell.

Tornquist-Plewa, Barbara and Krzysztof Stala, eds. 2011. Cultural Transformations after Communism. Central and Eastern Europe in Focus. Lund: Nordic Academic Press.

Urban, Michael. 2010. Cultures of Power in Post-Communist Russia. An Analysis of Elite Political Discourse. Cambridge: Cambridge University Press.

Whitefield, Stephen, ed. 2005. Political Culture and Post-Communism. Houndmills: Palgrave Macmillan. 